\title{
Vitamin D receptor in chondrocytes promotes osteoclastogenesis and regulates FGF23 production in osteoblasts
}

\author{
Ritsuko Masuyama, ${ }^{1}$ Ingrid Stockmans, ${ }^{1}$ Sophie Torrekens, ${ }^{1}$ Riet Van Looveren, ${ }^{1}$ \\ Christa Maes, ${ }^{1}$ Peter Carmeliet, ${ }^{2}$ Roger Bouillon, ${ }^{1}$ and Geert Carmeliet ${ }^{1}$ \\ ${ }^{1}$ Laboratory of Experimental Medicine and Endocrinology, Katholieke Universiteit Leuven, Leuven, Belgium. \\ ${ }^{2}$ Center for Transgene Technology and Gene Therapy, Flanders Interuniversity Institute for Biotechnology, Leuven, Belgium.
}

\begin{abstract}
Genomic actions induced by $1 \alpha 25$-dihydroxyvitamin $\mathrm{D}_{3}\left[1,25(\mathrm{OH})_{2} \mathrm{D}_{3}\right]$ are crucial for normal bone metabolism, mainly because they regulate active intestinal calcium transport. To evaluate whether the vitamin $\mathrm{D}$ receptor (VDR) has a specific role in growth-plate development and endochondral bone formation, we investigated mice with conditional inactivation of VDR in chondrocytes. Growth-plate chondrocyte development was not affected by the lack of VDR. Yet vascular invasion was impaired, and osteoclast number was reduced in juvenile mice, resulting in increased trabecular bone mass. In vitro experiments confirmed that VDR signaling in chondrocytes directly regulated osteoclastogenesis by inducing receptor activator of NF- $\kappa B$ ligand (RANKL) expression. Remarkably, mineral homeostasis was also affected in chondrocyte-specific VDR-null mice, as serum phosphate and $1,25(\mathrm{OH})_{2} \mathrm{D}$ levels were increased in young mice, in whom growth-plate activity is important. Both in vivo and in vitro analysis indicated that VDR inactivation in chondrocytes reduced the expression of FGF 23 by osteoblasts and consequently led to increased renal expression of $1 \alpha$-hydroxylase and of sodium phosphate cotransporter type IIa. Taken together, our findings provide evidence that VDR signaling in chondrocytes is required for timely osteoclast formation during bone development and for the endocrine action of bone in phosphate homeostasis.
\end{abstract}

\section{Introduction}

Vitamin D is the major regulator of calcium homeostasis and protects the organism from calcium deficiency via effects on the intestine, kidney, and bone. Vitamin D interacts with the vitamin D receptor (VDR), a transcription factor regulating gene expression in several cell types, including osteoblasts and chondrocytes. Disorders of the vitamin $\mathrm{D}$ endocrine system by mutations in or inactivation of the VDR (1-3) or the $1 \alpha$-hydroxylase gene, CYP27B1 (4-6), result in profound disturbances of mineral homeostasis and of bone mineralization. Decreased active intestinal calcium absorption due to reduced expression of epithelial calcium channels (7) is a crucial mechanism contributing to the phenotype. The importance of calcium absorption is further evidenced by the fact that calcium supplementation rescued hypocalcemia and hyperparathyroidism and restored bone mineralization both in patients and mice with loss of VDR function $(8,9)$, which raises questions about the role of VDR in bone metabolism. However, these data do not exclude the possibility that VDR may have a specific, although not essential, role in bone. Accordingly, the ability of osteoblasts to support osteoclastogenesis is regulated by but not dependent on vitamin D signaling (10). In addition, in vitro studies revealed

Nonstandard abbreviations used: BMD, bone mineral density; BV/TV, trabecular bone volume; Col2, collagen 2a1; Col2Cre, Cre driven by collagen 2 promoter; $\mathrm{Cre}^{-} V D R^{\mathrm{l} / \mathrm{fl}}, \mathrm{Col} 2 \mathrm{Cre}^{-/-} V D R^{\mathrm{fl} / \mathrm{fl}}$ (mice); HPRT, hypoxanthine-guanine phosphoribosyl transferase; NPT2a, sodium phosphate cotransporter type IIa; $1,25(\mathrm{OH})_{2} \mathrm{D}_{3}, 1 \alpha 25$ dihydroxyvitamin $\mathrm{D}_{3}$; OPG, osteoprotegerin; $\mathrm{PGE}_{2}$, prostaglandin $\mathrm{E}_{2} ; \mathrm{PTH}$, parathyroid hormone; qRT-PCR, quantitative real-time PCR; RANKL, receptor activator of NF-кB ligand; Runx2, runt-related transcription factor 2; TRAP, tartrate-resistant acid phosphatase; VDR, vitamin D receptor; VDRfl/fl, floxed VDR (mice).

Conflict of interest: The authors have declared that no conflict of interest exists. Citation for this article: J. Clin. Invest. 116:3150-3159 (2006). doi:10.1172/JCI29463. that osteoblasts lacking VDR demonstrate enhanced differentiation potential (11) although transgenic overexpression of VDR in mature osteoblasts suggests that VDR exerts an anabolic function in bone (12). Finally, growth-plate abnormalities in mice lacking VDR were observed before the onset of hypocalcemia (3), suggesting a defined role for VDR in endochondral-bone formation.

The start of endochondral ossification is characterized by differentiation of aggregated mesenchymal cells into chondrocytes forming cartilage elements that later evolve to hypertrophic and finally terminal differentiated chondrocytes. The latter region is subsequently invaded by blood vessels accompanied by osteoclasts and osteoblasts, thereby replacing the cartilage with bone and bone marrow (13). Vitamin D signaling may regulate this process, as enhanced vascular invasion is observed when mice are treated with $1 \alpha 25$-dihydroxyvitamin $\mathrm{D}_{3}\left[1,25(\mathrm{OH})_{2} \mathrm{D}_{3}\right]$, probably resulting from increased availability of VEGF (14).

Besides its role in calcium homeostasis, vitamin D also affects phosphate homeostasis by participating in a negative feedback loop with FGF23. The phosphaturic factor FGF23 is mainly produced by bone (15) and induces renal phosphate wasting by suppressing renal tubular sodium phosphate cotransporter type IIa (NPT2a) expression (16). Vitamin D enhances the production of FGF23, which in its turn suppresses renal CYP27B1 expression (16). Mice lacking VDR show decreased circulating FGF23 levels in agreement with the negative reciprocal regulation (17).

To elucidate the role of vitamin D genomic action during endochondral bone development under assumed normal mineral homeostasis, we generated mice lacking VDR specifically in chondrocytes. The inactivation of VDR in chondrocytes did not manifestly affect chondrocyte development. Yet trabecular bone volume $(\mathrm{BV} / \mathrm{TV})$ was increased in early life due to reduced osteoclast num- 
A Targeting construct; $p N T / N D R$

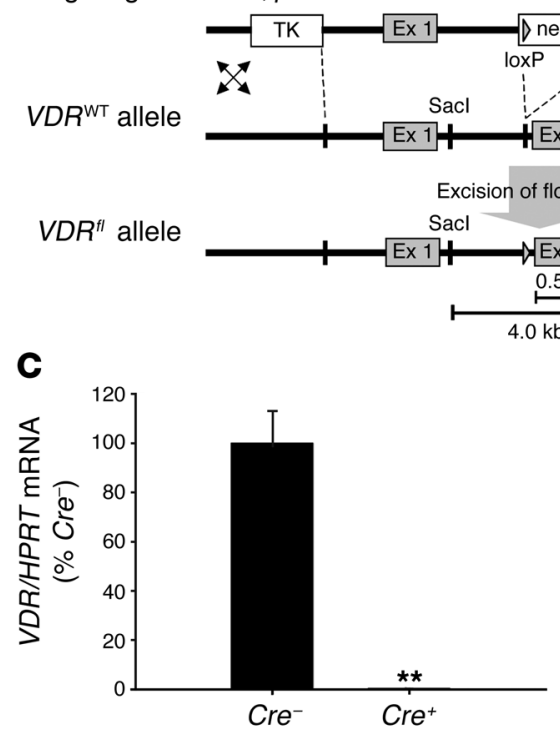

B $V D R^{\text {thoxtlox }}$
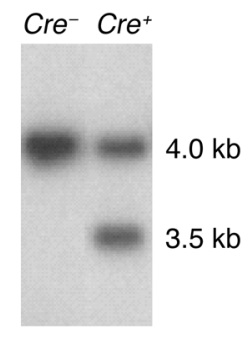

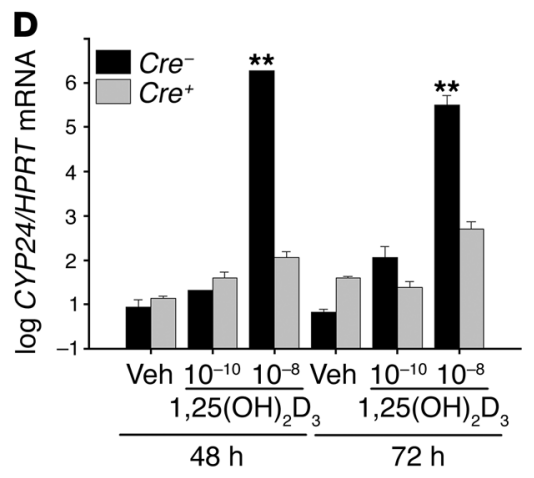

Figure 1

Inactivation of the VDR gene in chondrocytes. (A) Schematic representation of targeting construct pNT vector/VDR, the VDR ${ }^{W T}$ allele, and the $V D R^{f l}$ allele after Cre excision of the floxed neo cassette and probe used for identifying correct Cre excision of floxed exon 2. Restriction sites are indicated. Ex, exon. (B) Southern blot of Sacl-digested genomic DNA from Cre-VDR ${ }^{f l / f l}$ and $\mathrm{Cre}^{+} V D R^{f / f l}$ mice using internal probe. (C) VDR gene expression in growth-plate chondrocytes of $\mathrm{Cre}^{-} \mathrm{VDR} \mathrm{R}^{\mathrm{fl} / \mathrm{fl}}\left(\mathrm{Cre}^{-}\right)$and $\mathrm{Cre}^{+} V D R^{\text {fl/fII }}\left(\mathrm{Cre}^{+}\right)$mice $(n=6)$ was assessed by qRT-PCR analysis and calculated as a ratio to the $H P R T$ mRNA copies. Cre-VDR $R^{f / f l}$ value was set at $100 \%$. ${ }^{* \star} P<0.01$ versus $C r e-V D R^{f / / f I}$. (D) qRT-PCR analysis of CYP24 mRNA levels in primary chondrocyte culture stimulated with vehicle (veh) or $1,25(\mathrm{OH})_{2} \mathrm{D}_{3}\left(10^{-10} \mathrm{M}\right.$ and $\left.10^{-8} \mathrm{M}\right)$ for 48 hours and 72 hours. Values are corrected for HPRT mRNA copies and are shown as means \pm SEM in log scale. ${ }^{* *} P<0.01$ versus vehicle.

ber. In vitro experiments confirmed that VDR signaling in chondrocytes directly regulates osteoclastogenesis by inducing receptor activator of NF- $\mathrm{KB}$ ligand (RANKL) expression. Unexpectedly, serum phosphate and $1,25(\mathrm{OH})_{2} \mathrm{D}$ levels were increased in these mice before weaning. Both in vivo and in vitro analysis showed that normal FGF23 production by osteoblasts is dependent on VDR genomic action in chondrocytes. Taken together, these results show that VDR signaling in chondrocytes is required for timely osteoclastogenesis during bone development and regulates FGF23 production by osteoblasts.

\section{Results}

Loss of VDR in growth-plate chondrocytes does not affect their development. To evaluate the contribution of VDR in early endochondral-bone development, floxed VDR (VDR $\left.R^{f / f l}\right)$ mice were intercrossed with transgenic mice in which Cre recombinase was driven by collagen 2a1 (Col2) promoter (Figure 1A). The efficiency of chondrocyte-specific VDR inactivation was assessed at the DNA, RNA, and functional levels. Correct excision of the floxed VDR exon was demonstrated by Southern blot analysis of tail-extracted DNA from 15-day-old

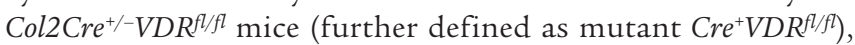
which was not observed in WT Col2Cre-/-VDR fl/fl $\left(\mathrm{Cre}^{-} V D R^{f l / f l}\right)$ mice. At this age, the tail vertebrae still contain collagen 2-expressing cells (Figure 1B). Analysis of VDR mRNA expression by quantitative real-time PCR (qRT-PCR) revealed undetectable VDR levels

mice (Figure 2, $\mathrm{C}$ and $\mathrm{D}$; only histology of 15 -day-old mice is shown.). The total length of the growth plate (data not shown) as well as the length of hypertrophic cartilage in tibiae of neonatal and 15-day-old mice were similar between the 2 genotypes (Figure 2E). Also, the amount of growth-plate mineralization in 8-week-old mice did not differ (Table 1). The mRNA level of Col2, a marker of proliferating chondrocytes, was assessed in neonatal, 15-day-old, and 8-week-old femora but was not significantly different between the 2 genotypes (Figure 2, F-H). In addition, its expression pattern in the growth plates of 15-day-old mice was indistinguishable between genotypes, as revealed by collagen 2 immunostaining (Supplemental Figure 1; supplemental material available online with this article; doi:10.1172/JCI29463DS1). Compared with Cre-VDR $R^{f / f l}$ mice, collagen 10 (Col10) mRNA level, a specific marker of hypertrophic chondrocytes, was unaltered in neonatal $\mathrm{Cre}^{+} V D R^{f / f l}$ mice (Figure $2 \mathrm{~F}$ ), decreased in 15-day-old mice $(P<0.05$; Figure $2 \mathrm{G}$ ), and at normal levels at the age of 8 weeks (Figure $2 \mathrm{H}$ ). These data suggest that lack of VDR in chondrocytes does not manifestly impair chondrocyte development but suppresses temporarily the terminal differentiation of the chondrocytes.

$B V / T V$ is increased in juvenile $C r e^{+} V D R^{f / f l}$ mice. During endochondral ossification, cartilage becomes progressively replaced by mineralized bone, which is a highly coordinated process, depending partially on factors produced by chondrocytes. To investigate the effect of VDR inactivation in chondrocytes on this process, trabec- 
Table 1

Bone parameters in 8-week-old mice

\begin{tabular}{|c|c|c|}
\hline & $C r e^{-V D R^{f / / t}}$ & $\mathrm{Cre}^{+} \mathrm{VDR}^{\mathrm{fl} / \mathrm{fl}}$ \\
\hline Femur length (mm) & $15.24 \pm 0.17$ & $14.97 \pm 0.22$ \\
\hline Trabecular BMD (mg/cm³) & $119.9 \pm 15.2$ & $147.1 \pm 10.8$ \\
\hline Cortical BMD (mg/cm³) & $1174 \pm 5$ & $1186 \pm 6$ \\
\hline Tibia BV/TV $(\%)$ & $6.49 \pm 1.59$ & $6.05 \pm 0.84$ \\
\hline BFR/BS $\left(\mu \mathrm{m}^{3} / \mu \mathrm{m}^{2} /\right.$ day $\left.\times 10^{-2}\right)$ & $62.11 \pm 6.17$ & $67.79 \pm 7.10$ \\
\hline Growth-plate mineralization area (\%) & $11.78 \pm 0.64$ & $11.65 \pm 0.78$ \\
\hline
\end{tabular}

$\mathrm{BFR} / \mathrm{BS}$, bone formation ratio.

ular bone parameters were quantified at several ages. At 8 weeks, static and dynamic bone parameters were normal, as evidenced by similar values between the 2 genotypes for trabecular and cortical bone mineral density (BMD) analyzed by peripheral quantitative computed tomography of the femur, BV/TV quantified on von Kossa-stained sections, and bone formation ratio (BFR/BS) assessed on unstained sections of the tibiae (Table 1).

In contrast, $\mathrm{BV} / \mathrm{TV}$ was significantly increased, by $50 \%$, in neonatal and 15-day-old $\mathrm{Cre}^{+} V D R^{f / f l}$ compared with $\mathrm{Cre}^{-} V D R^{\ell / f l}$ mice (Figure 3A). In addition, von Kossa staining revealed that trabecular bone extended more deeply into the metaphyseal area of the proximal tibiae in 15-day-old $\mathrm{Cr}^{+} V D R^{f / / l}$ mice (Figure 3, B and C).

Vascularization and osteoclast invasion are delayed when chondrocytes lack $V D R$. The observed changes in bone mass in 15-day-old $\mathrm{Cre}^{+} V D R^{f / f l}$ mice may have resulted from increased bone formation and/or decreased bone resorption. Osteoblast function was not manifestly changed by VDR inactivation in chondrocytes, as suggested by the normal mRNA expression of the osteoblastic marker osteocalcin (Figure 3D) and runt-related transcription factor 2 (Runx2) (data not shown) in 15-day-old femora. In addition, in vitro osteogenic differentiation of bone marrow stromal cells (CFU-osteoblast) isolated from 15-day-old mice did not differ between genotypes, as comparable number and size of colonies staining positive for alkaline phosphatase or alizarin red were obtained (data not shown).
On the other hand, bone resorption may be impaired; this is often associated at these stages with changes in vascularization. These processes were investigated at E15.5 and in neonatal and 15-dayold mice. Initial blood vessel invasion in $\mathrm{Cre}^{-} V D R^{\ell / / f}$ tibiae, assessed by CD31 staining, was observed at E15.5, showing endothelial cells located at the bone collar/perichondrium but also invading the cartilage core (Figure 4, A and B). In contrast, in $\mathrm{Cr}^{+} V D R^{\ell / f l}$ mice, endothelial cells were solely detected along the bone collar/perichondrium (Figure 4, C and D). At the same time, tartrate-resistant acid phosphatase-positive (TRAP-positive) multinuclear osteoclasts accompanying endothelial cells had just started to invade the tibial cartilage, forming the primary ossification center in $\mathrm{Cre}^{-} V D R^{\mathrm{l} / \mathrm{fl}}$ tibiae (Figure 4, F and G) whereas these cells were hardly observed in $\mathrm{Cre}^{+} V D R^{f / f l}$ tibiae (Figure 4, H and I). Quantification revealed that blood vessel invasion in $\mathrm{Cre}^{+} V D R^{f / f l}$ tibiae was only $57 \%$ of

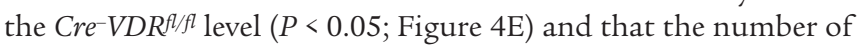
TRAP-positive cells even decreased, with $70 \%$ in $\mathrm{Cre}^{+} V D R^{f / f l}$ tibiae compared with $\mathrm{Cre}^{-V} V R^{\ell / f l}(P<0.05$; Figure 4J).

In neonatal tibiae, the number of blood vessels invading the terminal row of the hypertrophic chondrocytes of the growth plate was reduced in $C r e^{+} V D R^{f / f l}$ mice (Figure 5B) as compared with $\mathrm{Cre}^{-} V D R^{f / f l}$ mice (Figure $5 \mathrm{~A}$ ). Accordingly, intercapillary distance was significantly larger in neonatal $\mathrm{Cr}^{+} V D R^{f / f l}$ tibiae $(P<0.05$; Figure 5E). Also, in 15-day-old $\mathrm{Cre}^{+} V D R^{\ell / f l}$ mice, the intercapillary distance was significantly increased both at the terminal row of the growth plate and in the metaphysis, $150 \mu \mathrm{m}$ distal from the hypertrophic chondrocytes (Figure 5E). The changes in vascularization were accompanied by alterations in osteoclast formation, as shown by the reduced TRAP positivity in $\mathrm{Cre}^{+} V D R^{\ell / f l}$ mice (Figure 5D) compared with $\mathrm{Cre}^{-V D R^{f / f l}}$ mice (Figure 5C). The number of TRAP-positive cells at the border of the growth plate was decreased by $50 \%$ in neonatal $\mathrm{Cre}^{+} V D R^{f / f l}$ tibiae (Figure $5 \mathrm{~F}$ ). This was reflected in a significant reduction of the calcitonin receptor mRNA level, a marker of differentiated osteoclasts, in $\mathrm{Cre}^{+} V D R^{\mathrm{t} / f l}$ mice (Figure $5 \mathrm{H}$ ). Also, at 15 days, osteoclast surface in trabecular bone was decreased in $\mathrm{Cre}^{+} V D R^{l / f l}$ tibiae (Figure 5G). These 2 processes, osteoclast formation and angiogenesis, are regulated by the
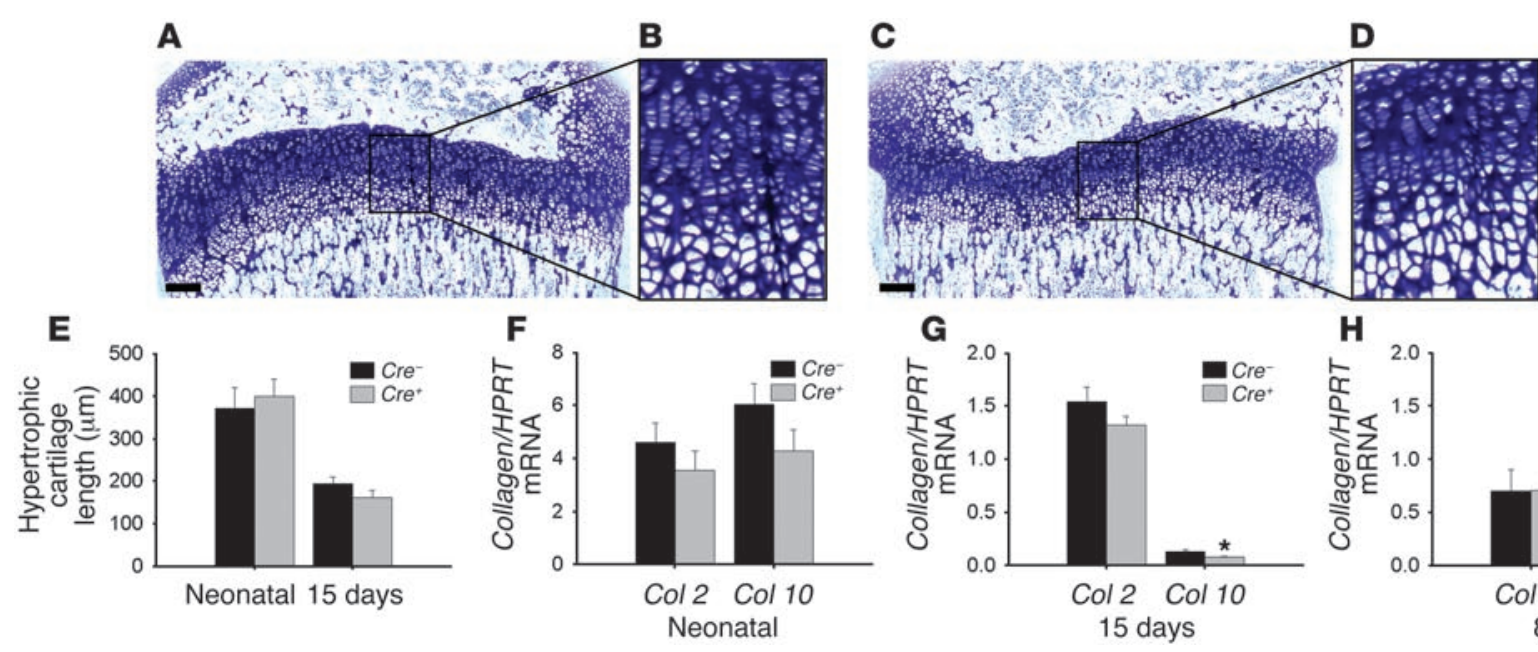

Figure 2

Normal growth-plate development in chondrocyte-specific VDR-null mice. (A-D) Toluidine blue staining of the proximal tibiae from 15-day-old $\mathrm{Cre}^{-V D D R^{f / / f l}}(\mathbf{A}$ and $\mathbf{B})$ and $C \mathrm{C}^{+} V D R^{f / / f l}$ mice $(\mathbf{C}$ and $\mathbf{D})$. Scale bar: $200 \mu \mathrm{m}$. (E) Quantification of the length of the hypertrophic cartilage zone in the proximal tibiae. $(\mathbf{F}-\mathbf{H})$ Gene expression of Col2 and Col10 in neonatal $(\mathbf{F})$, 15-day-old $(\mathbf{G})$, and 8-week-old $(\mathbf{H})$ femora from Cre-VDR $R^{f l / f l}$ and

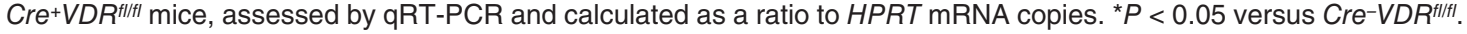



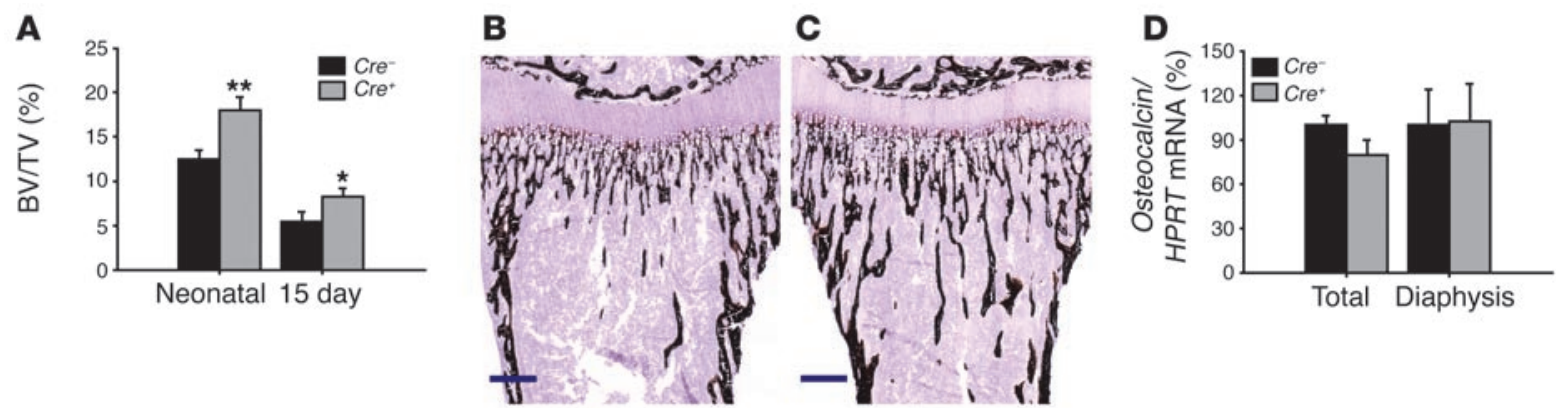

Figure 3

Chondrocyte-specific VDR inactivation results in increased metaphyseal bone volume in neonatal and 15-day-old mice. (A) Quantification of $\mathrm{BV} / \mathrm{TV}$ in the proximal tibiae metaphysis on von Kossa-stained sections shows a significant increase in BV/TV in Cre $+V D R^{f / / f l}$ mice compared with

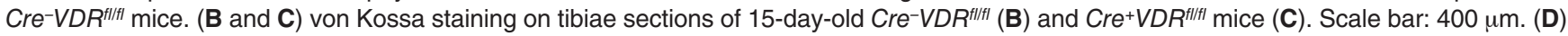
Osteocalcin gene expression in femora (total bone or dissected diaphysis) of 15-day-old Cre-VDR $R^{f / f l}$ and Cre+VDR $R^{f / / f l}$ mice was assessed by qRTPCR analysis and calculated as a ratio to the HPRT mRNA copies. Cre-VDR $R^{f / f \mid}$ value was set at $100 \%$. ${ }^{*} P<0.05 ;{ }^{* *} P<0.01$ versus $C r e-V D R^{f \mid / f l}$.

secreted factors RANKL and VEGF, respectively. In agreement with the histological findings, mRNA expression of both factors was significantly reduced in neonatal $C r e^{+} V D R^{f l / f l}$ femora compared with $C r e^{-} V D R^{f l / f l}$ mice $(P<0.05$; Figure $5 \mathrm{H})$. These data indicate that vascular invasion at the growth plate and resorption of trabecular bone is decreased in $\mathrm{Cre}^{+} V D R^{f l f l}$ mice, which can explain the observed increased bone volume.

Chondrocytes promote osteoclastogenesis by $1,25(\mathrm{OH})_{2} \mathrm{D}_{3}$-induced $R A N K L$ expression. Since $C r e^{+} V D R^{f / f l}$ mice displayed retarded osteoclast invasion into cartilage and reduced RANKL gene expression in neonatal femora, we investigated whether $1,25(\mathrm{OH})_{2} \mathrm{D}_{3}$ genomic signaling in chondrocytes regulates osteoclastogenesis, using cocultures with spleen cells. TRAP-positive multinuclear cells were formed in $1,25(\mathrm{OH})_{2} \mathrm{D}_{3}$-treated $\left(10^{-8} \mathrm{M}\right)$ cocultures of calvarial-derived osteoblasts and splenocytes irrespective of the genotype (Figure 6, A and B; only results of $\mathrm{Cre}^{-} V D R^{f l / f l}$ splenocytes are shown). Under similar experimental conditions, chondrocytes isolated from $\mathrm{Cre}^{-} V D R^{f l / f l}$ mice induced TRAP-positive multinuclear osteoclasts in cocultures with splenocytes from either genotype (Figure 6C). However, no osteoclasts were formed when $C r e^{+} V D R^{f / f l}$ chondrocytes were used (Figure 6D). This effect was specific for the $1,25(\mathrm{OH})_{2} \mathrm{D}_{3} / \mathrm{VDR}$ signaling pathway, as prostaglandin $\mathrm{E}_{2}$ $\left(\mathrm{PGE}_{2}\right)\left(10^{-6} \mathrm{M}\right)$ induced osteoclast formation irrespective of the chondrocyte genotype (Figure 6, E and F).

As osteoclastogenesis is dependent on the ratio of RANKL to osteoprotegerin (OPG), the mRNA level of these factors was quantified in $1,25(\mathrm{OH})_{2} \mathrm{D}_{3}$ - or $\mathrm{PGE}_{2}$-treated primary cultures and compared with vehicle treatment. RANKL gene expression was significantly induced in osteoblasts $(P<0.001)$ regardless of the genotype and stimulus (Figure $6 \mathrm{G})$. In addition, $1,25(\mathrm{OH})_{2} \mathrm{D}_{3}\left(10^{-8} \mathrm{M}\right)$ increased RANKL expression 30-fold in $\mathrm{Cr}^{-} V D R^{f l / f l}$ chondrocytes $(P<0.001)$ whereas no induction was noticed in $C r e^{+} V D R^{f / f l}$ chon-
A

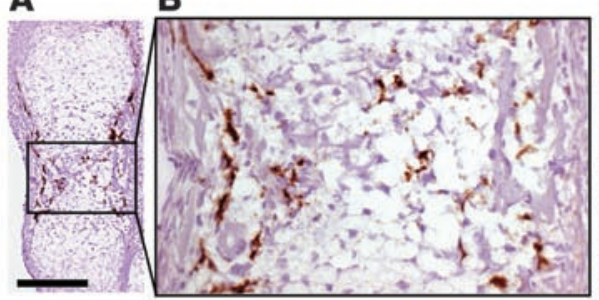

$\mathbf{F}$

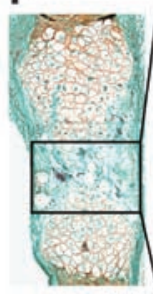

G

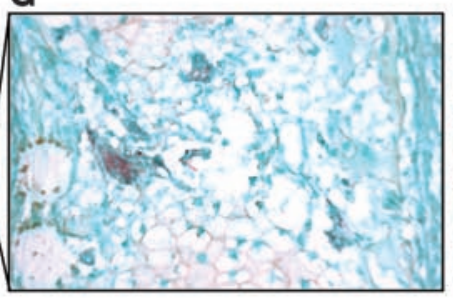

C

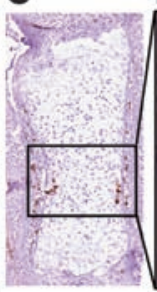

H

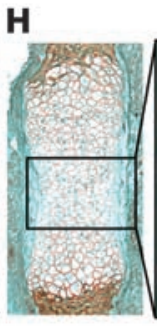

D

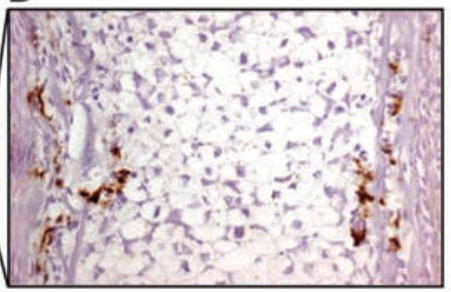

I

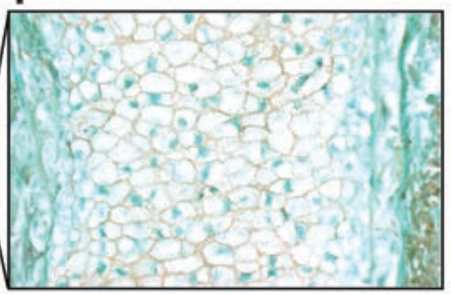

E

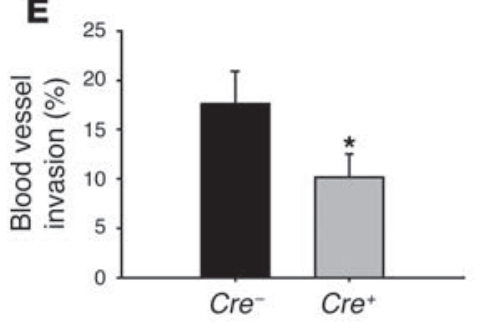

$\mathbf{J}$

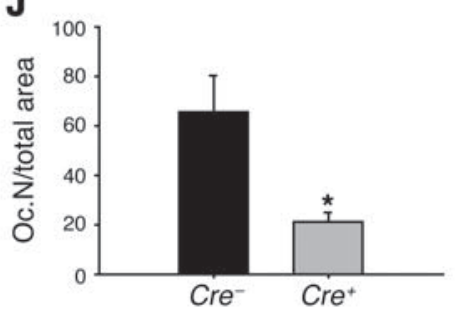

Figure 4

Vascular invasion and osteoclast formation are impaired in E15.5 Cre+VDR fl/fl mice. (A-D, F-I) Sets of adjacent tibial sections were immunostained for CD31 (A-D) or TRAP (F-I) to visualize endothelial cells or osteoclasts in E15.5 Cre-VDR $R^{f / f l}(\mathbf{A}, \mathbf{B}, \mathbf{F}$, and $\mathbf{G})$ and $C r e^{+} V D R^{f l / f l}(\mathbf{C}, \mathbf{D}, \mathbf{H}$, and I) mice, respectively. Scale bar: $200 \mu \mathrm{m}$. (E) Invasion of blood vessels from the perichondrium into the cartilage core was measured and expressed relative to the cartilage width in Cre+VDR $R^{f / f l}$ and Cre-VDR $R^{f / f t}$ tibiae. (J) Quantification of the number of osteoclasts (Oc.N) in the primary ossification center. ${ }^{*} P<0.05$ versus $C r e-V D R^{f|l| t l}$. 
A

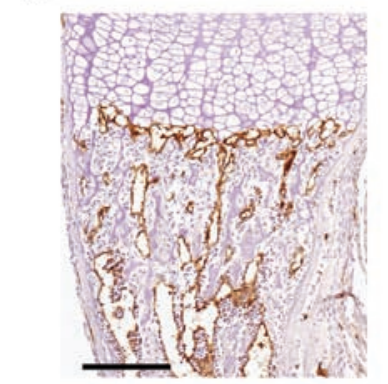

E

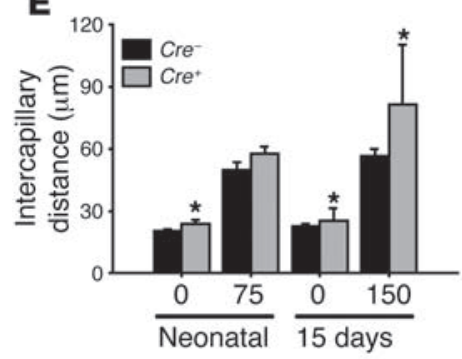

B

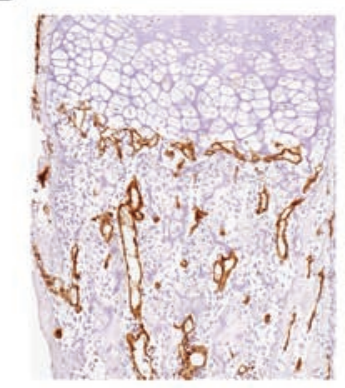

F

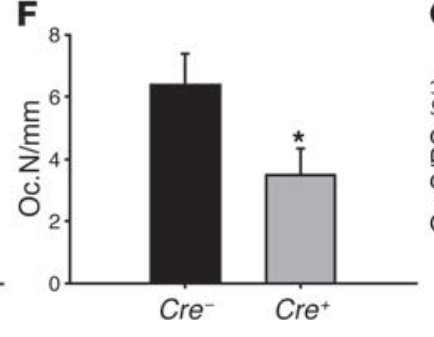

c

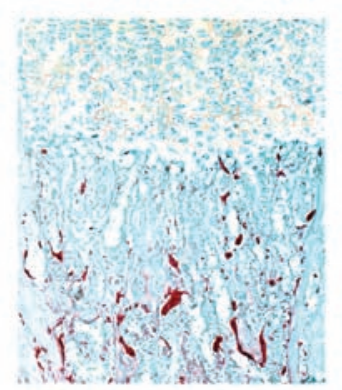

G

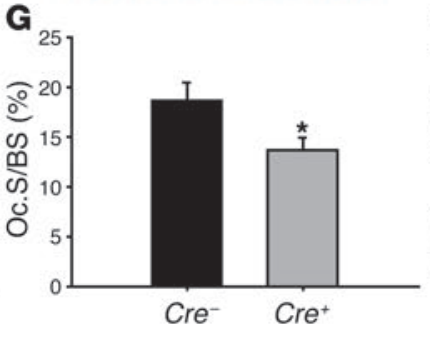

D

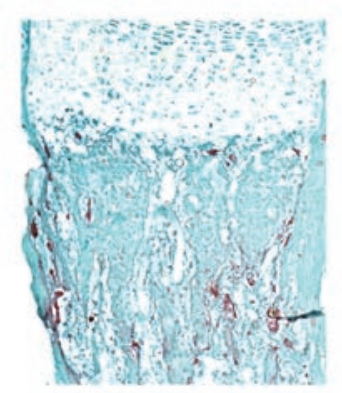

H

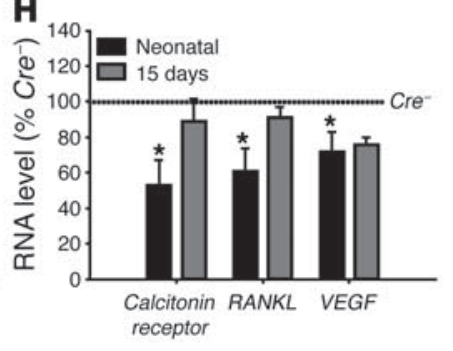

Figure 5

Decreased vascularization and osteoclast number in neonatal and 15-day-old Cre+VDR $R^{f / f t}$ mice. (A-D) Endothelial cells and osteoclasts were visualized by CD31 (A and B) and TRAP (C and D) staining, respectively, in neonatal Cre-VDR $R^{f l / f l}(\mathbf{A}$ and $\mathbf{C})$ and Cre ${ }^{+V D R^{f l / f l}}(\mathbf{B}$ and $\mathbf{D})$ tibiae. Scale bar: $200 \mu \mathrm{m}$. (E) Intercapillary distance, measured at 0, 75, and $150 \mu \mathrm{m}$ from the growth-plate border in neonatal and 15-day-old tibiae was larger in $C r e+V D R^{f / f l}$ mice compared with $C r e-V D R^{f l / f l}$ mice. $(\mathbf{F})$ The number of osteoclasts at the terminal row of hypertrophic chondrocytes in neonatal tibiae was significantly lower in $\mathrm{Cre}^{+} V D R^{\text {fl/fl }}$ mice. (G) Osteoclast surface (Oc.S) was significantly decreased in 15-day-old Cre ${ }^{+V}$ VDR $R^{\text {fl/fl }}$ tibiae. (H) Calcitonin receptor, RANKL, and VEGF mRNA levels in neonatal and 15-day-old Cre+VDR fl/fl femora was determined by qRT-PCR, corrected for HPRT mRNA copies, and expressed relative to Cre-VDR ${ }^{f / f t}$ mice set at $100 \%$. ${ }^{*} P<0.05$ versus Cre $^{-V} V D R^{f l / f l}$.

drocytes (Figure 6G). On the other hand, $\mathrm{PGE}_{2}$ significantly induced RANKL expression in chondrocytes from either genotype (Figure 6G). OPG mRNA levels did not differ in any condition. Thus, these findings clearly indicate that chondrocytes can promote osteoclast differentiation by expressing RANKL, which is strongly induced by $1,25(\mathrm{OH})_{2} \mathrm{D}_{3}$ genomic signaling.

$1,25(\mathrm{OH})_{2} \mathrm{D}_{3}$ genomic signaling in chondrocytes modulates phosphaturic factor expression. In systemic VDR-null mice, mineral homeostasis becomes manifestly disturbed after weaning, concurrent with the development of skeletal changes. In the present study, we investigated serum biochemistry at the age of 15 days, when endochondral ossification was clearly affected in $C r e^{+} V D R^{f l / f l}$ mice. Chondrocyte-specific VDR inactivation did not affect calcium and parathyroid hormone (PTH) levels (Table 2). On the other hand, phosphate and $1,25(\mathrm{OH})_{2} \mathrm{D}$ serum concentrations were significantly increased in $\mathrm{Cre}^{+} V D R^{f / f l}$ mice compared with $C r e^{-V} V R^{f l f l}$ mice $(P<0.05$; Table 2$)$. These changes were no longer observed in 8-week-old mice, as both serum phosphate $\left(13.5 \pm 0.6 \mathrm{mg} / \mathrm{dl}\right.$ in $C r e^{-V D} R^{f l / f l}$ versus $12.9 \pm 0.8 \mathrm{mg} / \mathrm{dl}$

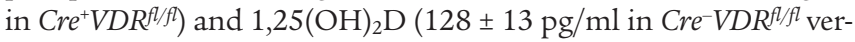
sus $121 \pm 1 \mathrm{pg} / \mathrm{ml}$ in $\left.\mathrm{Cre}^{+} V D R^{f / f l}\right)$ showed normal values.

Since phosphate homeostasis is mainly regulated by renal phosphate reabsorption, we assessed the expression of NPT2a, the major player in this process, expressed at the apical membrane of proximal tubular cells. Immunohistochemical staining showed more abundant NPT2a expression in 15-day-old Cre ${ }^{+} V D R^{f l / f l}$ kidneys (Figure 7B) compared with $C r e^{-} V D R^{f l / f l}$ kidneys (Figure 7A), which is in agreement with the increased serum phosphate level. Quantification of renal NPT2 a mRNA level by qRT-PCR revealed a 4-fold increase in $C r e^{+} V D R^{f l / f l}$ mice $(P<0.05$; Figure $7 C)$, confirming the immunohistochemical analysis. Concerning $1,25(\mathrm{OH})_{2} \mathrm{D}$ serum lev- els, these are mainly regulated by renal CYP27B1 expression, which hydroxylates 25 -hydroxyvitamin $\mathrm{D}$ to its active form. In accordance with the increased $1,25(\mathrm{OH})_{2} \mathrm{D}$ serum levels, CYP27B1 mRNA level was significantly increased in $C r e^{+} V D R^{f / f l}$ kidney $(P<0.01$; Figure 7D) while gene expression of the catabolic enzyme CYP24 was not changed (Figure 7E). It is noteworthy that no difference in renal VDR mRNA levels was observed between the 2 genotypes (Figure 7F).

These data suggest a link between the altered renal expression of these 2 genes and VDR inactivation in chondrocytes. A plausible factor that may affect $1,25(\mathrm{OH})_{2} \mathrm{D}$ as well as phosphate serum levels is FGF23, as FGF23 suppresses the expression of the renal phosphate transporter NPT2a and of CYP27B1 (16). In addition, bone has been identified as the largest source and regulatory site of FGF23, and FGF23 expression is induced by $1,25(\mathrm{OH})_{2} \mathrm{D}_{3}(17)$. Accordingly, FGF23 mRNA level was significantly decreased in $\mathrm{Cre}^{+} V D R^{f / f l}$ femora of 1 -week-old and 15-day-old mice, as revealed by qRT-PCR $(P<0.01$; Figure $7 \mathrm{G})$. In addition, FGF23 serum levels were $43 \%$ lower in 15 -day-old $C r e^{+} V D R^{f l / f l}$ mice compared with $\mathrm{Cre}^{-V D R^{f / f l} \text { mice }(}(P<0.01$; Figure $7 \mathrm{H})$. As with the age-related changes of serum phosphate and $1,25(\mathrm{OH})_{2} \mathrm{D}$ levels, no difference in FGF23 serum levels was observed between the 2 genotypes in 8-weekold mice $\left(71.4 \pm 6.3 \mathrm{pg} / \mathrm{ml}\right.$ in $\mathrm{Cre}^{-} V D R^{f / f l}$ versus $76.9 \pm 12.2 \mathrm{pg} / \mathrm{ml}$ in $C r e^{+} V D R^{f l / f l}$ mice). These data indicate that the increased phosphate and $1,25(\mathrm{OH})_{2} \mathrm{D}$ serum concentrations before weaning are likely caused by decreased FGF23 production in bone, leading to increased renal NPT2 $a$ and CYP27B1 mRNA expression.

Genomic action of $1,25(\mathrm{OH})_{2} \mathrm{D}_{3}$ in chondrocytes regulates $F G F 23$ expression in osteoblasts in vitro. In bone, the cells identified as producing FGF23 are osteoblasts and osteocytes. To elucidate whether chondrocytes express FGF23 and whether this expression is regulated by 
A

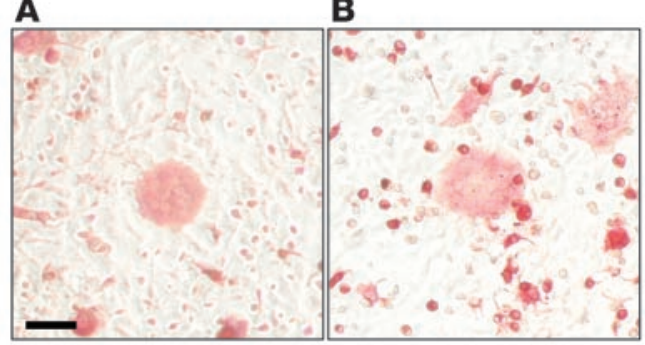

$\mathbf{E}$

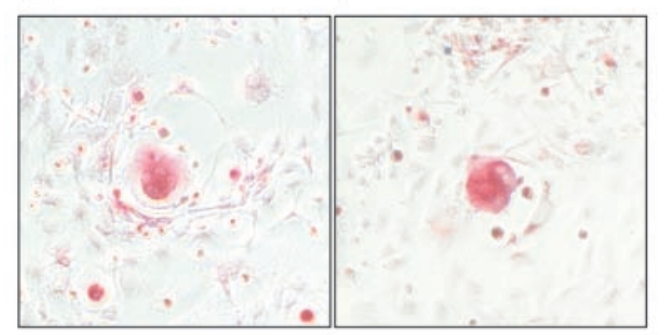

C

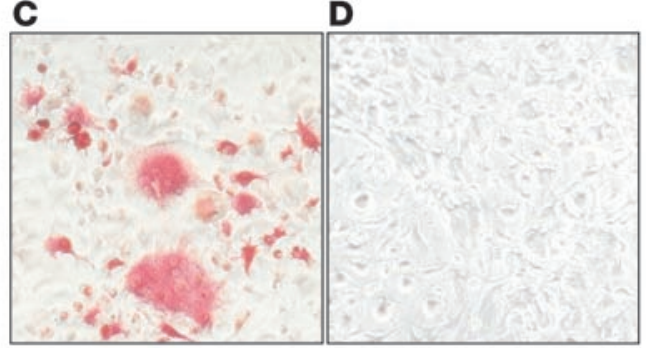

G

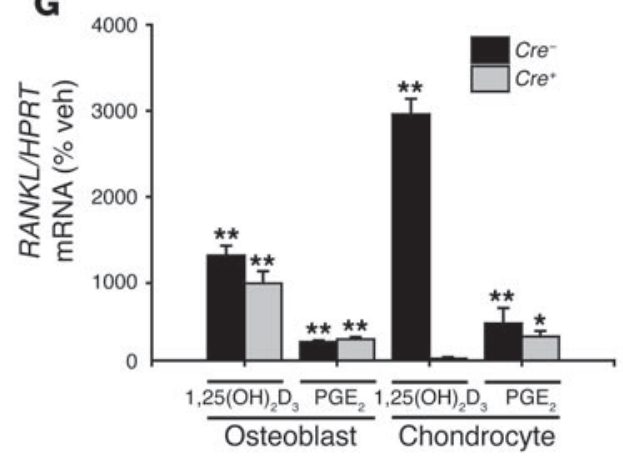

Figure 6

Signaling of $1,25(\mathrm{OH})_{2} \mathrm{D}_{3}$ in chondrocytes promotes osteoclast differentiation by the RANKL pathway. (A-F) Microscopic observation of TRAP-positive multinuclear cells formed after 1 week of coculturing osteoblasts or chondrocytes with Cre-VDR ${ }^{f / f l}$ splenocytes. Osteoclast formation was similar whether osteoblasts from Cre-VDR $R^{f / f I}(\mathbf{A})$ or $C r e^{+} V D R^{f / / f l}$ mice $(\mathbf{B})$ were used and treated with $1,25(\mathrm{OH})_{2} \mathrm{D}_{3}\left(10^{-8} \mathrm{M}\right)$. Chondrocytes from

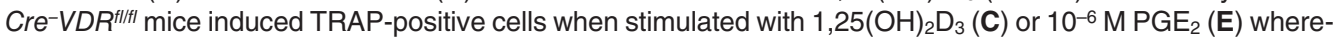
as chondrocytes from $\mathrm{Cre}^{+} V D R^{f \mid l f l}$ mice induced osteoclasts only when treated with $\mathrm{PGE}_{2}(\mathbf{F})$ and not with $1,25(\mathrm{OH})_{2} \mathrm{D}_{3}$ (D). Scale bar: $100 \mu \mathrm{m}$. (G) qRT-PCR analysis of $R A N K L$ mRNA expression in primary osteoblast or chondrocyte cultures from Cre-VDR $R^{f / f l}$ and $C r e^{+} V D R^{f / f I}$ mice stimulated by $10^{-8} \mathrm{M} 1,25(\mathrm{OH})_{2} \mathrm{D}_{3}$ or $10^{-6} \mathrm{M}$ $\mathrm{PGE}_{2}$ for 2 days. Values are calculated as ratio to HPRT mRNA copies and expressed relative to vehicle set as $100 \%$. ${ }^{\star} P<0.05 ;{ }^{*} P<0.01$ versus vehicle.

$1,25(\mathrm{OH})_{2} \mathrm{D}_{3}$, in vitro experiments were performed. Treatment with $1,25(\mathrm{OH})_{2} \mathrm{D}_{3}\left(10^{-8} \mathrm{M}, 48\right.$ hours $)$ induced FGF23 mRNA expression 100 -fold in primary osteoblasts derived from either $C r e^{+} V D R^{f l / f l}$ or $C r e^{-V D R}{ }^{f l / f l}$ mice (Figure 8A). On the other hand, the FGF23 message was undetectable in cultured primary chondrocytes, both in basal conditions and after $1,25(\mathrm{OH})_{2} \mathrm{D}_{3}$ treatment (data not shown). These data indicate that FGF23 expression is restricted to osteoblasts and suggest that the reduced FGF23 expression in $\mathrm{Cr} e^{+} V D R^{f / f l}$ mice most likely results from altered expression of a chondrocytederived factor due to lack of VDR action. Several in vitro experiments were performed to investigate this hypothesis. First, metatarsals at E16.5, a stage when interaction between osteoblasts and chondrocytes is abundantly present, were cultured for 24 hours, after which 1 metatarsal was treated with $1,25(\mathrm{OH})_{2} \mathrm{D}_{3}\left(10^{-8} \mathrm{M}\right)$ and the contralateral with vehicle. The relative induction of FGF23 mRNA by $1,25(\mathrm{OH})_{2} \mathrm{D}_{3}$ treatment was significantly higher in $C r e^{-} V D R^{f l / f l}$ than in $C r e^{+} V D R^{f l / f l}$ metatarsals $(P<0.005$; Figure $8 \mathrm{~B})$. However, the number of osteoblasts in the metatarsals may be different between the 2 genotypes, as vascular invasion and formation of the primary ossification center is delayed in $C r e^{+} V D R^{f / f l}$ metatarsals (Figure 4). We therefore introduced a coculture system of primary osteoblasts and chondrocytes to characterize more precisely their interaction on FGF23 expression. Primary chondrocytes were isolated from both genotypes and cultured during 4 days, after which osteoblasts isolated from $C r e^{-} V D R^{f l / f l}$ calvaria were added to the culture. Treatment with $1,25(\mathrm{OH})_{2} \mathrm{D}_{3}$ induced FGF23 mRNA expression by the osteoblasts and Col10 expression by the chondrocytes were comparable (data not shown). The induction of FGF23 mRNA level by $1,25(\mathrm{OH})_{2} \mathrm{D}_{3}$ was significantly higher in osteoblasts cultured with $C r e^{-V D R} R^{f / f l}$ chondrocytes than in cultures with $C r e^{+} V D R^{f l / f l}$ chondrocytes $(P<0.001$; Figure $8 \mathrm{D})$. In addition, $1,25(\mathrm{OH})_{2} \mathrm{D}_{3}$-treated osteoblasts showed a more pronounced induction of FGF23 mRNA levels when cultured with $\mathrm{Cre}^{-V D R^{f l / f l}}$ chondrocytes in the Transwell system than when cultured alone (compare FGF23 mRNA level in Figure 8D with level in Figure 8A). In agreement with the results of mRNA expression, FGF23 protein level was more increased in conditioned media from cocultures with $C r e^{-V D R^{f l f l}}$ chondrocytes than from cultures with $C r e^{+} V D R^{f / f l}$ chondrocytes $(P<0.01$; Figure $8 \mathrm{E})$. These results indicate that vitamin $\mathrm{D}$ genomic signaling in chondrocytes contributes to FGF23 expression in osteoblasts by altering the expression of a secreted factor.

\section{Discussion}

VDR is a $1,25(\mathrm{OH})_{2} \mathrm{D}_{3}$-regulated transcription factor required for normal mineral and skeletal homeostasis, which it contributes to mainly by regulating intestinal calcium absorption. The predominant effects of vitamin D deficiency or resistance before the end of puberty are impaired bone mineralization and abnormal growth-plate structure. Both can be corrected by a high-calcium diet. Nevertheless, a specific but possibly redundant role for VDR in bone metabolism has been suggested by in vitro data using VDR-null cells (11) and by in vivo overexpression of VDR in osteoblasts (12). To elucidate the function 
Table 2

Serum biochemistry in 15-day-old mice

\begin{tabular}{|c|c|c|}
\hline & $\mathrm{Cre}^{-V D R^{f / f I I}}$ & $\mathrm{Cre}^{+} V D R^{f I / f I}$ \\
\hline Calcium (mg/dl) & $10.57 \pm 0.08$ & $10.77 \pm 0.08$ \\
\hline Phosphate (mg/dl) & $12.87 \pm 0.56$ & $14.33 \pm 0.40^{A}$ \\
\hline PTH (pg/ml) & $31.42 \pm 2.89$ & $37.37 \pm 6.20$ \\
\hline $1,25(\mathrm{OH})_{2} \mathrm{D}(\mathrm{pg} / \mathrm{ml})$ & $74.88 \pm 3.56$ & $127.40 \pm 15.86^{A}$ \\
\hline
\end{tabular}

${ }^{A} P<0.05$ versus $C r e^{-V D D R^{f / t}}$.

of VDR during endochondral bone development, we generated mice with chondrocyte-specific inactivation of VDR. Loss of VDR in chondrocytes did not interfere with chondrocyte development but resulted unexpectedly in increased trabecular bone mass during early postnatal life due to reduced osteoclastogenesis accompanied by decreased vascularization. In addition, serum $1,25(\mathrm{OH})_{2} \mathrm{D}$ and phosphate levels were transiently increased in juvenile mice; this resulted from decreased FGF23 production by osteoblasts. Taken together, these data reveal what we believe to be a novel role for VDR in chondrocytes as regulators of osteoclastogenesis and controllers of phosphate homeostasis, which they achieve by affecting FGF23 production.

During endochondral bone development, chondrocytes proliferate and subsequently differentiate into hypertrophic chondrocytes that finally undergo apoptosis while being replaced by bone. Chondrocytes lacking VDR expression develop normally; this agrees with previous findings in VDR-null mice (3). In this latter model, the typical morphology of rickets with enlargement of the zone of hypertrophic chondrocytes mainly develops after weaning $(2,3,7)$. These features can be rescued by a high-calcium/high-lactose diet, which suggests an indirect function of VDR. Recently, Sabbagh et al. (18) demonstrated that rickets is due to impaired apoptosis of the late hypertrophic chondrocytes secondary to hypophosphatemia. Consistent with this model, the length of the zone of hypertrophic chondrocytes in chondrocyte-specific VDR-null mice was not altered, as calcium level was normal and phosphate level was even increased. Rather, a temporary decrease in the differentiation of hypertrophic chondrocytes was observed, as Col10 expression was reduced in 15 -day-old mice. These results indicate that VDR expression in chondrocytes does not contribute to the proliferation of chondrocytes but rather minimally affects hypertrophic differentiation.

During hypertrophic differentiation, chondrocytes synthesize VEGF, a key regulator of vascular invasion, first at the primary ossification center and later at the growth plate; these are essential steps in endochondral ossification. Deficient VEGF synthesis by hypertrophic chondrocytes (19) or reduced release of VEGF from the matrix (20) due to MMP-9 inactivation results in decreased vascular invasion at the growth plate and expansion

\section{Figure 7}

Chondrocyte-specific VDR inactivation affects phosphate-vitamin D homeostasis by decreasing FGF23 expression in bone. (A and B) Immunohistochemical staining of renal NPT2a in 15-day-old Cre-VDR $R^{\text {Il/fl }}$ (A) and $\mathrm{Cre}^{+} V D R^{\text {fl/fl}}$ (B) mice. Scale bar: $50 \mu \mathrm{m}$. (C-G) qRT-PCR analysis of renal NPT2a (C), CYP27B1 (D), CYP24 (E), and VDR (F) mRNA expression in 15-day-old mice and of $F G F 23(\mathbf{G})$ mRNA expression in 1-week-old and 15-day-old femora, corrected for HPRT mRNA levels. $\mathrm{Cre}^{+} V D R^{f / f / l}$ values are expressed relative to $C r e^{-V} V R^{f / f / l}$ set at $100 \%$. (H) Serum FGF23 level was significantly decreased in 15-day-old

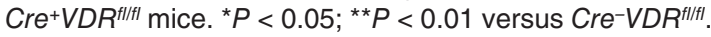

of the hypertrophic chondrocyte layer. As a known regulator of VEGF transcription, $1,25(\mathrm{OH})_{2} \mathrm{D}_{3}$ promotes vascularization at the growth plate (14). In agreement with these findings, the present results now reveal that VDR inactivation in chondrocytes results in decreased VEGF expression before weaning, associated with a reduced number of blood vessels at the border of the growth plate. Also, at the stage of primary ossification during embryonic bone development, chondrocytic VDR-null tibiae exhibited decreased angiogenic invasion into the cartilage anlage compared with $V D R$ WT mice. However, at 8 weeks, blood vessel invasion at the growth plate was normal, suggesting that this process was rescued. This temporary phenomenon is also observed in MMP-9-null mice, in which the enlarged hypertrophic chondrocyte zone is only detected until 8 weeks (20). Taken together, these results indicate that timely VEGF mRNA expression by hypertrophic chondrocytes, required for vascular invasion of this zone, is partly dependent on $1,25(\mathrm{OH})_{2} \mathrm{D}_{3}$ genomic action.

Concomitant with vascular invasion, the calcified matrix surrounding hypertrophic chondrocytes became degraded by chondroclasts/ osteoclasts. In embryonic tibiae, the number of TRAP-positive multinuclear cells was significantly reduced when VDR expression was lacking in chondrocytes. Also, at later ages, fewer osteoclasts were detected, particularly at the border of the growth plate but also in the proximal diaphysis. These data were corroborated by decreased mRNA expression of calcitonin receptor, a specific marker for osteoclasts.
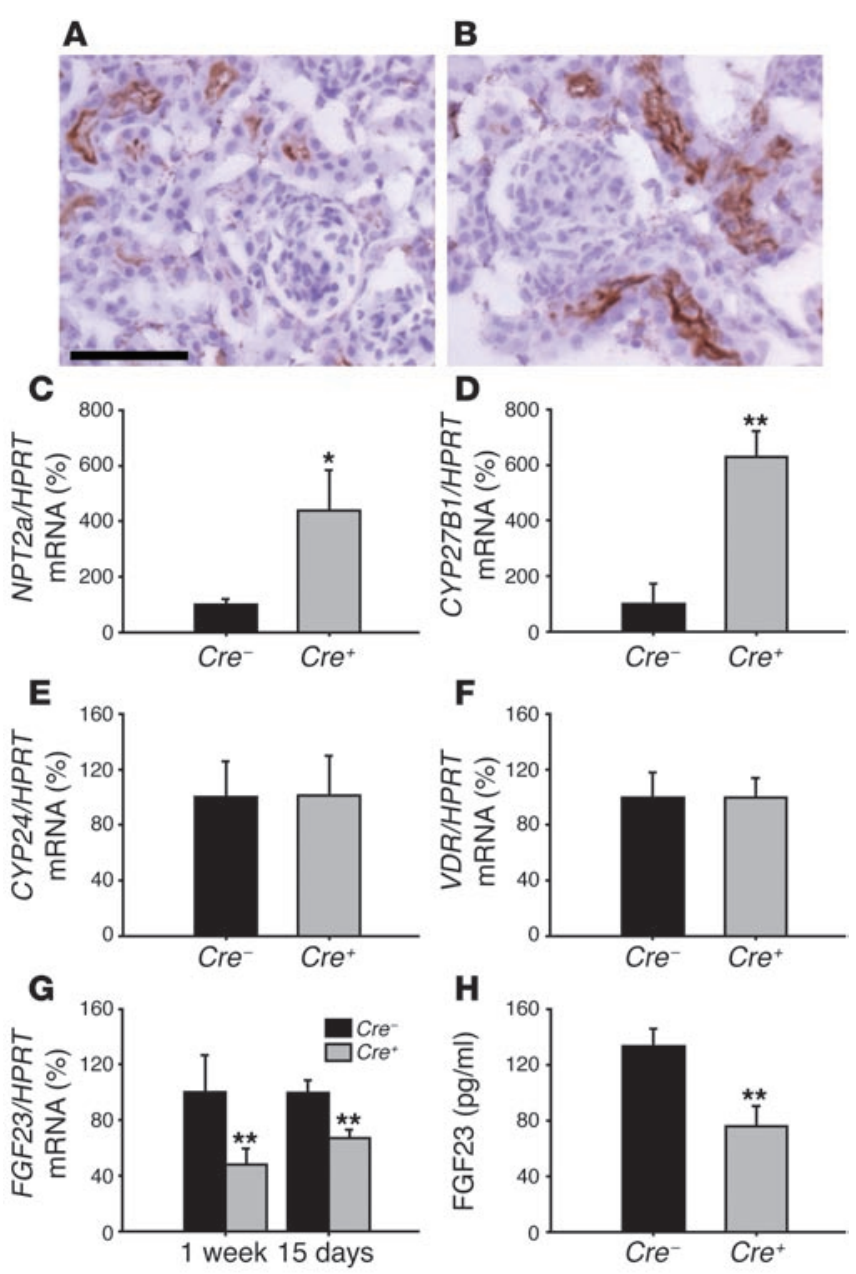
A
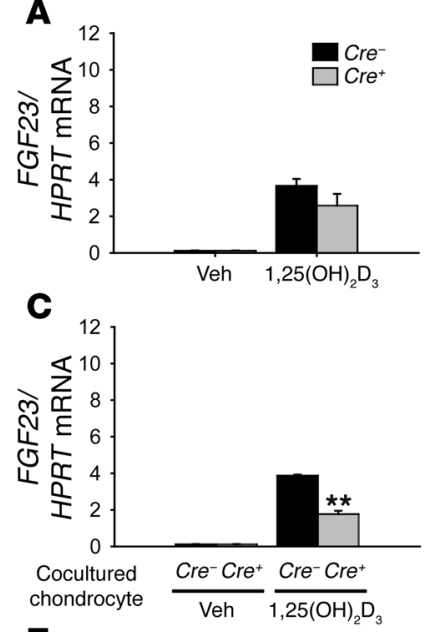

$\mathbf{E}$

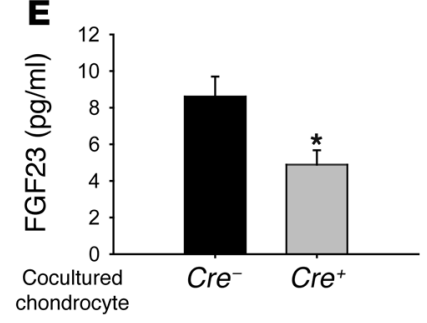

A plausible explanation for the reduced number of osteoclasts is impaired expression of RANKL, an essential factor in osteoclastogenesis. This factor is mainly produced by osteoblasts or mesenchymal cells under the control of several cytokines and hormones, including $1,25(\mathrm{OH})_{2} \mathrm{D}_{3}(21)$. We identified a novel role for chondrocytes in supporting osteoclastogenesis by expressing RANKL, an effect regulated by $1,25(\mathrm{OH})_{2} \mathrm{D}_{3}$ genomic action. The evidence therefore is provided by both in vivo and in vitro findings. First, RANKL mRNA expression was decreased in neonatal femora lacking VDR expression in chondrocytes. Second, growthplate chondrocytes expressed RANKL in vitro, confirming a recent finding by Takamoto et al. (22). Comparable to WT osteoblasts, the mRNA expression of RANKL in WT chondrocytes was increased by $1,25(\mathrm{OH})_{2} \mathrm{D}_{3}$ treatment whereas this induction was lacking in VDR-deficient chondrocytes. Third, WT chondrocytes supported osteoclastogenesis in $1,25(\mathrm{OH})_{2} \mathrm{D}_{3}$-treated cocultures with splenocytes although less efficiently than WT osteoblasts. Osteoclasts were, however, not formed when chondrocytes lacked VDR. It is noteworthy that RANKL expression and osteoclast formation were normal when $V D R$-deficient chondrocytes were stimulated with $\mathrm{PGE}_{2}$, reminiscent of the osteoblast characteristics derived from systemic VDR-null mice (10).

These results indicate that $1,25(\mathrm{OH})_{2} \mathrm{D}_{3}$ genomic action in chondrocytes contributes to normal RANKL expression and timely osteoclast invasion in the primary ossification center and later at the border of hypertrophic chondrocytes during metaphyseal growth. The observed decrease in osteoclastogenesis in $\mathrm{Cr}^{+} V D R^{f l / f l}$ mice may also explain the increased BV/TV observed before weaning. Moreover, no changes in osteoblast parameters were noticed at these stages, as both Runx2 and osteocalcin mRNA expression did not differ between genotypes. Additionally, in vitro osteogenic differentiation of bone marrow stromal cells was not altered in $C r e^{+} V D R^{f l} / f l$ mice. The increase in bone mass was

\section{Figure 8}

Signaling of $1,25(\mathrm{OH})_{2} \mathrm{D}_{3}$ in chondrocytes supports FGF23 expression in osteoblasts. (A-D) qRT-PCR analysis of FGF23 mRNA expression in primary osteoblast cultures (A), in E16.5 metatarsal cultures (B), in cocultures of chondrocytes and osteoblasts (C), and in primary osteoblasts cultured in the Transwell system with chondrocytes cultured on the membrane (D), corrected for HPRT mRNA copies. Cultures derived from $\mathrm{Cre}^{-} \mathrm{VDR} \mathrm{R}^{\mathrm{fl|fl}}$ or $\mathrm{Cre}^{+} \mathrm{VDR} \mathrm{R}^{\mathrm{flffl}}$ mice were treated with $1,25(\mathrm{OH})_{2} \mathrm{D}_{3}\left(10^{-8} \mathrm{M}\right)$ for 48 hours or vehicle. FGF23 mRNA expression in $1,25(\mathrm{OH})_{2} \mathrm{D}_{3}$-treated metatarsals is depicted as an increase relative to its vehicle-treated contralateral (B). (E) FGF23 protein level was measured in the culture media of the Transwell system after $1,25(\mathrm{OH})_{2} \mathrm{D}_{3}$ treatment. In the cocultures, only $\mathrm{Cre}-\mathrm{VD} R^{\text {fl/tIl }}$ osteoblasts were used whereas the genotype of the chondrocytes varied as indicated. ${ }^{*} P<0.05 ;{ }^{* *} P<0.005$ versus $C r e-V D R^{f \mid l f l}$.

only observed in juvenile mice. This is consistent with the temporary role of the growth plate, which remains active through puberty but fuses in adult mice.

Bone metabolism and mineral homeostasis are closely interconnected and regulated mainly by the hormones $1,25(\mathrm{OH})_{2} \mathrm{D}_{3}$ and PTH. As elucidated in this study, $1,25(\mathrm{OH})_{2} \mathrm{D}_{3}$ genomic actions directly affect endochondral bone development by regulating specific gene expression. The $1,25(\mathrm{OH})_{2} \mathrm{D}_{3} / \mathrm{VDR}$ pathway also plays a role in mineral homeostasis, mainly by inducing intestinal and renal calcium transporter gene expression, thereby promoting calcium (re)absorption. The effect of $1,25(\mathrm{OH})_{2} \mathrm{D}_{3}$ on phosphate homeostasis is, however, more complex, as it stimulates phosphate (re)absorption both directly (23) and indirectly by downregulating PTH secretion (24) while, on the other hand, it increases FGF23 secretion, thereby promoting renal phosphate excretion (16). In this latter pathway, $1,25(\mathrm{OH})_{2} \mathrm{D}_{3}$ stimulates FGF23 expression in osteoblasts, which in turn decreases renal $1 \alpha$-hydroxylase expression and NPT2 apical localization, resulting in impaired phosphate reabsorption. This suggests that bone is involved in mineral homeostasis, which it contributes to not only by releasing calcium and phosphate but also by secreting this phosphaturic factor.

We now provide evidence that VDR action in chondrocytes contributes to this endocrine negative feedback loop between $1,25(\mathrm{OH})_{2} \mathrm{D}_{3}$ and FGF23. In 15-day-old chondrocyte-specific VDRnull mice, serum $1,25(\mathrm{OH})_{2} \mathrm{D}$ and phosphate levels were significantly increased, an unexpected finding. The increased $1,25(\mathrm{OH})_{2} \mathrm{D}$ levels correlated with and most likely resulted from enhanced renal CYP27B1 mRNA levels in these mice. Likewise, the increased phosphate levels can be explained by abundant NPT2a localization at the apical membrane, as shown by immunohistochemistry, and by enhanced NPT $2 a$ mRNA expression. In contrast, serum calcium and PTH levels were normal and therefore provide no explanation for the altered serum $1,25(\mathrm{OH})_{2} \mathrm{D}$ and phosphate levels. Searching for the signaling mechanism between VDR inactivation in chondrocytes and altered renal expression of CYP27B1 and NPT2a, we investigated the expression of the major phosphatonin FGF23. FGF23 mRNA levels were decreased in bone from chondrocyte-specific VDR-null mice, which explains the decreased serum FGF23 levels in these mice, as bone is the major source of circulating FGF23. This reduced FGF23 level can clarify the increased CYP27B1 and NPT2 expression in the kidney, which in its turn results in increased $1,25(\mathrm{OH})_{2} \mathrm{D}$ and phosphate levels in chondrocyte-specific $V D R$-null mice. It is noteworthy that renal CYP24 expression was not affected in chondrocyte-specific $V D R$-null mice, despite the increased serum $1,25(\mathrm{OH})_{2} \mathrm{D}$ level. However, FGF23 has recently been reported to 
induce CYP24 expression in the kidney (25). A plausible explanation reconciling both findings is that the decreased circulating FGF23 levels in chondrocyte-specific $V D R$-null mice neutralize the inducing effect of $1,25(\mathrm{OH})_{2} \mathrm{D}$ on renal CYP2 4 expression.

The contribution of chondrocytes to FGF23 expression in bone is most likely indirect, as we noticed that chondrocytes do not express FGF23. The present data reveal that a soluble chondrocyte-derived factor induced by $1,25(\mathrm{OH})_{2} \mathrm{D}_{3}$ genomic signaling contributes to FGF23 expression in osteoblasts. To date, the mechanism of FGF23 induction by $1,25(\mathrm{OH})_{2} \mathrm{D}_{3}$ is still not fully characterized. Transcriptional regulation via VDR has been proposed although a VDRE has not yet been identified in the promoter region of FGF23. In addition, indirect regulation by an intermediary factor has been suggested $(17,26)$. We now expand this model by adding a paracrine factor secreted by chondrocytes in a $1,25(\mathrm{OH})_{2} \mathrm{D}_{3}$-dependent manner. Further investigations are necessary to identify this unknown factor.

The biological effect of VDR inactivation in chondrocytes is observed in early life but is transient. Indeed, the relative increase in bone mass, renal CYP27B1 expression, serum $1,25(\mathrm{OH})_{2} \mathrm{D}_{3}$, and phosphate disappeared at 8 weeks of age when the growth plate of mice became less active as the long bones nearly attained their final length.

In conclusion, the present study indicates that $1,25(\mathrm{OH})_{2} \mathrm{D}_{3}$ genomic action in chondrocytes is not crucial for growth-plate development but regulates via paracrine factors bone development and phosphate homeostasis. These vitamin D-regulated genes are essential for timely vascularization and osteoclast invasion into the hypertrophic chondrocyte zone and participate in the interactive loop between FGF23 and $1,25(\mathrm{OH})_{2} \mathrm{D}_{3}$. This study also elucidates a novel function for chondrocytes as coplayers in the endocrine function of bone.

\section{Methods}

Animals. Targeted mutagenesis to generate $V D R^{f / f l}$ mice was achieved by homologous and Cre/loxP-mediated site-specific recombination in embryonic stem cells. The targeting vector consisted of cDNA containing lox $\mathrm{P}$ sites upstream and downstream of exon 2 (Figure 1A), as described previously (7). Chondrocyte-specific inactivation of VDR was obtained by crossing $V D R^{\ell / f l}$ mice with transgenic mice expressing Cre recombinase under the control of Col2 gene promoter (27). After appropriate breeding, $\mathrm{Cre}^{+} V D R^{f / f l}$ and $\mathrm{Cre}^{-} V D R^{f / f l}$ littermates were used in the analysis. Genotyping was performed by Southern blot analysis or PCR of genomic DNA extracted from tail biopsies. All mice were bred in our animal housing facilities (Proefdierencentrum Leuven) and received normal diet containing $1.1 \%$ calcium and $0.8 \%$ phosphate (Standard; Carfil Quality-Pavan Service). These experiments were approved by the ethical committee of Katholieke Universiteit Leuven.

The age of the embryos was stated as E0.5, which was the morning a vaginal plug was observed after overnight mating. When indicated, mice received 2 intraperitoneal injections of the fluorochrome calcein $(16 \mathrm{mg} / \mathrm{kg}$; SigmaAldrich) 7 and 3 days before sacrifice. Blood was collected, and kidneys, intestine, and bones were dissected and processed as described $(7,28)$.

Serum biochemistry. Calcium and phosphate were analyzed by SYNCHRON Clinical System (Beckman Coulter). Levels of $1,25(\mathrm{OH})_{2} \mathrm{D}$ and PTH were determined using [ $\left.{ }^{125} \mathrm{I}\right] 1,25(\mathrm{OH})_{2} \mathrm{D}$ RIA kit (DiaSorin) and mouse-PTH ELISA kit (Immutopics), respectively. FGF23 protein levels in serum and cell culture media were determined using Human Intact FGF-23 ELISA kit (Kainos Laboratories Inc.) ( $n=6$ per genotype).

Bone length and BMD of the femur. The left femur of 8-week-old mice $(n=8$ per genotype) was fixed in Burkhardt's solution. The length was measured using a caliper (Digimatic; Mitutoyo), and BMD was assessed by quantitative computed tomography, using Stratec XCT Research $\mathrm{M}^{+}$(Norland Medical Systems Inc.) (29).

Histology, immunohistochemistry, and histomorphometry. Tibiae from E15.5 ( $n=6-7$ per genotype), neonatal $(n=8), 15$-day-old $(n=8)$, and 8-week-old $(n=8)$ mice were analyzed. Left tibiae were fixed in Burkhardt's solution, embedded undecalcified in methyl methacrylate, and sectioned at $10 \mu \mathrm{m}$. Right tibiae were fixed in $2 \%$ paraformaldehyde, decalcified in $0.5 \mathrm{M}$ EDTA ( $\mathrm{pH} 7.4$ )/PBS prior to dehydration, embedded in paraffin, and sectioned at $5 \mu \mathrm{m}$.

For general morphological analysis, decalcified sections were stained with Harris H\&E or with $2 \%$ toluidine blue. Methyl methacrylate sections were stained according to the von Kossa method to assess mineralized bone. Osteoclasts were visualized on paraffin sections reacted for TRAP activity (28). Additional sections were used for CD31 and collagen 2 staining as previously described $(28,30)$. Histomorphometric analysis was done as previously described $(28,29)$, using a Kontron Elektronik image-analyzing system (KS 400 V 3.00; Zeiss). Dynamic bone parameters were calculated using formulas described previously (31).

Kidneys were incubated overnight in 30\% sucrose after fixation in $4 \%$ paraformaldehyde for 2 hours, embedded in Shandon Cryomatrix (Thermo Electron Corp.), and sectioned at $5 \mu \mathrm{m}$. Immunohistochemical staining for NPT2a was performed with rabbit anti-NPT2a in 1:400 dilutions (32) followed by incubation with horseradish peroxidase-conjugated goat anti-rabbit immunoglobulin (EnVision system; Dako). Harris H\&E was used for counterstaining.

Primary osteoblast, chondrocyte, and bone marrow stromal cell cultures and cocultures. Primary growth-plate chondrocytes were isolated from proximal tibiae and distal femora of 3 -day-old mice by $0.2 \%$ collagenase-A digestion (30). From the same mice, primary osteoblasts were isolated from calvaria by sequential digestion with $0.1 \%$ collagenase $\mathrm{A}$ and $0.2 \%$ dispase. Osteoblastic cells from the second to fifth fraction were pooled (33). Cells were cultured for 4 days $\left(40,000\right.$ cells $\left./ \mathrm{cm}^{2}\right)$, then treated with $10^{-8} \mathrm{M}$ and $10^{-10} \mathrm{M} 1,25(\mathrm{OH})_{2} \mathrm{D}_{3}$ (a kind gift from J.P. Vandevelde, Solvay, Weesp, The Netherlands), $10^{-6} \mathrm{M} \mathrm{PGE}_{2}$, (Sigma-Aldrich), or vehicle for another 2 or 3 days, whereafter cells were harvested for RNA isolation. Bone marrow stromal cells isolated from 15-day-old femora were cultured according to the method described previously (34). To assess CFU osteoblast, cells were cultured in 6-well plates $\left(52,000 \mathrm{cells} / \mathrm{cm}^{2}\right)$ for 10 days and 21 days, whereafter they were stained for alkaline phosphatase or with alizarin red, respectively (34).

The regulation of FGF23 expression was studied in cocultures of primary osteoblasts and chondrocytes. Two types of coculture were used: either the 2 cell types were cultured adjacent to each other or they were cultured separated by a membrane. In the first condition, $\mathrm{Cre}^{-} V D R^{\ell / / f l}$ or $\mathrm{Cre}^{+} V D R^{f / / f l}$ chondrocytes were cultured in 12-well plates $\left(40,000\right.$ cells $\left./ \mathrm{cm}^{2}\right)$ in DMEM/ F12 (1:1) (Invitrogen) supplemented with $10 \%$ FCS, $50 \mu \mathrm{g} / \mathrm{ml}$ ascorbic acid, and $100 \mu \mathrm{g} / \mathrm{ml}$ sodium pyruvate for 4 days, whereafter primary $\mathrm{Cre}^{-} V D R^{f / f l}$ osteoblasts $\left(40,000\right.$ cells $\left./ \mathrm{cm}^{2}\right)$ were added. In the second setup, the same cell types were used, but chondrocytes were cultured on BD Falcon cell culture insert ( $16,000 \mathrm{cells} / \mathrm{cm}^{2}$; pore size $\left.0.4 \mu \mathrm{m}\right)$, and after 4 days, osteoblasts were seeded in the lower well. After 2 days, cocultures were treated with $10^{-8} \mathrm{M}$ $1,25(\mathrm{OH})_{2} \mathrm{D}_{3}$ for 48 hours. All quantifications were performed on 4 wells per group and repeated 2 to 4 times.

In vitro osteoclast differentiation. Osteoclast formation was studied in cocultures of primary osteoblasts or chondrocytes and spleen cells using all 4 combinations of genotypes. Osteoblasts $\left(23,000 \mathrm{cells} / \mathrm{cm}^{2}\right)$ or chondrocytes $\left(45,000\right.$ cells $\left./ \mathrm{cm}^{2}\right)$ were cultured in 8 -well chamber slides (Lab-Tek II; Nunc) in $\alpha$-MEM/10\% FCS for 6 hours, whereafter spleen cells $\left(230,000\right.$ cells $\left./ \mathrm{cm}^{2}\right)$ were added. Cultures were treated with $10^{-8} \mathrm{M}$ $1,25(\mathrm{OH})_{2} \mathrm{D}_{3}$ or $10^{-6} \mathrm{M} \mathrm{PGE}_{2}$ for 7 days, with medium and factors replaced 
every 2 days. At the end of the culture period, cells were stained for TRAP (33). TRAP-positive multinuclear cells containing more than 3 nuclei were identified as osteoclasts.

Metatarsal cultures. Right and left metatarsals were dissected from E16.5 embryos ( $n=6$ per genotype), stripped of skin and surrounding tissues, and cultured on a BD Falcon insert membrane (pore size, $0.4 \mu \mathrm{m}$ ) in 12-well plates in BGJb medium (Invitrogen) supplemented with $0.1 \%$ BSA, $25 \mu \mathrm{g} / \mathrm{ml}$ ascorbic acid, and $10 \mathrm{mM} \beta$-glycerophosphate. After 24 hours, the right metatarsal was treated with $10^{-8} \mathrm{M} 1,25(\mathrm{OH})_{2} \mathrm{D}_{3}$ and the contralateral with vehicle for 2 days, whereafter RNA was isolated.

Isolation of RNA and qRT-PCR. Total RNA of femora from neonatal, 1-weekold, 15-day-old, and 8-week-old mice ( $n=8$ per group), of kidneys from 15 -day-old mice ( $n=8$ per group), and of cultured metatarsals was extracted with TRIzOL (Invitrogen). RNA from cultured chondrocytes or osteoblasts was isolated using TRIzOL LS (Invitrogen) or RNeasy Mini Kit (QIAGEN). Subsequently, cDNA was synthesized using reverse transcriptase SuperScript II RT (Invitrogen). Real-time qRT-PCR was performed on an ABI Prism 7700 Sequence Detector (Applied Biosystems). Specific forward and reverse oligonucleotide primers and probes with fluorescent dye (FAM) and quencher (TAMRA) were used for calcitonin receptor, Col2, Col10, CYP24, CYP27B1, FGF23, $O P G$, osteocalcin, RANKL, Runx2, VEGF, and VDR. Expression levels were normalized for bypoxanthine-guanine phosphoribosyl transferase (HPRT) expression
(Supplemental Table 1). NPT2a mRNA expression was analyzed by TaqMan Gene Expression Assays (ID Mm00441450 m1; Applied Biosystems).

Statistics. Results are expressed as the mean \pm SEM. To assess the effect of genotype or treatment, data were compared by 2 -tailed Student's $t$ test or Mann-Whitney $U$ test after $F$ test using StatView (SAS) software. $P<0.05$ was considered significant.

\section{Acknowledgments}

We are grateful to R. Behringer for providing Col2a1 Cre mice, to J. Biber for providing NPT2a antiserum, and to N. Smets, I. Jans, K. Moerman, and A. Vanden Bosch for technical help. This work was supported by a grant from the Fund for Scientific Research-Flanders (FWO; G. 0508.05). C. Maes is a postdoctoral fellow from FWO (Belgium).

Received for publication June 21, 2006, and accepted in revised form September 19, 2006.

Address correspondence to: Geert Carmeliet, Laboratory of Experimental Medicine and Endocrinology, $\mathrm{O} \& \mathrm{~N}$, Gasthuisberg, Herestraat 49, B-3000 Leuven, Belgium. Phone: 32-16-34-5974; Fax:32-16-34-5934; E-mail: geert.carmeliet@med.kuleuven.be.
1. Haussler, M.R., et al. 1998. The nuclear vitamin D receptor: biological and molecular regulatory properties revealed. J. Bone Miner. Res. 13:325-349.

2. Yoshizawa, T., et al. 1997. Mice lacking the vitamin $D$ receptor exhibit impaired bone formation, uterine hypoplasia and growth retardation after weaning. Nat. Genet. 16:391-396.

3. Li, Y.C., et al. 1997. Targeted ablation of the vitamin $\mathrm{D}$ receptor: an animal model of vitamin D-dependent rickets type II with alopecia. Proc. Natl. Acad. Sci. U. S. A. 94:9831-9835.

4. Kitanaka, S., et al. 1998. Inactivating mutations in the 25-hydroxyvitamin $\mathrm{D}_{3} 1 \alpha$-hydroxylase gene in patients with pseudovitamin D-deficiency rickets. N. Engl. J. Med. 338:653-661.

5. Panda, D.K., et al. 2001. Targeted ablation of the 25 hydroxyvitamin D $1 \alpha$-hydroxylase enzyme: evidence for skeletal, reproductive, and immune dysfunction. Proc. Natl. Acad. Sci. U. S. A. 98:7498-7503.

6. Dardenne, O., Prud'homme, J., Arabian, A., Glorieux, F.H., and St-Arnaud, R. 2001. Targeted inactivation of the 25-hydroxyvitamin $\mathrm{D}_{3}-1 \alpha$-hydroxylase gene (CYP27B1) creates an animal model of pseudovitamin D-deficiency rickets. Endocrinology. 142:3135-3141.

7. Van Cromphaut, S.J., et al. 2001. Duodenal calcium absorption in vitamin D receptor-knockout mice: functional and molecular aspects. Proc. Natl. Acad. Sci. U. S. A. 98:13324-13329.

8. Balsan, S., et al. 1986. Long-term nocturnal calcium infusions can cure rickets and promote normal mineralization in hereditary resistance to 1,25 dihydroxyvitamin D. J. Clin. Invest. 77:1661-1667.

9. Amling, M., et al. 1999. Rescue of the skeletal phenotype of vitamin $\mathrm{D}$ receptor-ablated mice in the setting of normal mineral ion homeostasis: formal histomorphometric and biomechanical analyses. Endocrinology. 140:4982-4987.

10. Takeda, S., et al. 1999. Stimulation of osteoclast formation by 1,25 -dihydroxyvitamin $D$ requires its binding to vitamin D receptor (VDR) in osteoblastic cells: studies using VDR knockout mice. Endocrinology. 140:1005-1008.

11. Sooy, K., Sabbagh, Y., and Demay, M.B. 2005. Osteoblasts lacking the vitamin D receptor display enhanced osteogenic potential in vitro. J. Cell. Biochem. 94:81-87.

12. Gardiner, E.M., et al. 2000. Increased formation and decreased resorption of bone in mice with elevated vitamin D receptor in mature cells of the osteoblastic lineage. FASEB J. 14:1908-1916.

13. Karsenty, G., and Wagner, E.F. 2002. Reaching a genetic and molecular understanding of skeletal development. Dev. Cell. 2:389-406.

14. Lin, R., et al. 2002. $1 \alpha, 25$-dihydroxyvitamin $\mathrm{D}_{3}$ promotes vascularization of the chondro-osseous junction by stimulating expression of vascular endothelial growth factor and matrix metalloproteinase 9. J. Bone Miner. Res. 17:1604-1612.

15. Mirams, M., Robinson, B.G., Mason, R.S., and Nelson, A.E. 2004. Bone as a source of FGF23: regulation by phosphate? Bone. 35:1192-1199.

16. Saito, H., et al. 2003. Human fibroblast growth factor- 23 mutants suppress $\mathrm{Na}^{+}$-dependent phosphate co-transport activity and $1 \alpha, 25$-dihydroxyvitamin $\mathrm{D}_{3}$ production. J. Biol. Chem. 278:2206-2211.

17. Kolek, O.I., et al. 2005. $1 \alpha, 25$-Dihydroxyvitamin $\mathrm{D}_{3}$ upregulates FGF23 gene expression in bone: the final link in a renal-gastrointestinal-skeletal axis that controls phosphate transport. Am. J. Physiol. Gastrointest. Liver Physiol. 289:G1036-G1042.

18. Sabbagh, Y., Carpenter, T.O., and Demay, M.B. 2005. Hypophosphatemia leads to rickets by impairing caspase-mediated apoptosis of hypertrophic chondrocytes. Proc. Natl. Acad. Sci. U. S. A. 102:9637-9642.

19. Haigh, J.J., Gerber, H.P., Ferrara, N., and Wagner, E.F. 2000. Conditional inactivation of VEGF-A in areas of collagen2a 1 expression results in embryonic lethality in the heterozygous state. Development. 127:1445-1453.

20. Vu, T.H., et al. 1998. MMP-9/gelatinase B is a key regulator of growth plate angiogenesis and apoptosis of hypertrophic chondrocytes. Cell. 93:411-422.

21. Yasuda, H., et al. 1998. Osteoclast differentiation factor is a ligand for osteoprotegerin/osteoclastogenesis-inhibitory factor and is identical to TRANCE/RANKL. Proc. Natl. Acad. Sci. U. S. A. 95:3597-3602.

22. Takamoto, M., et al. 2003. Hedgehog signaling enhances core-binding factor a 1 and receptor activator of nuclear factor-kappaB ligand (RANKL) gene expression in chondrocytes. J. Endocrinol. 177:413-421.

23. Yamamoto, H., et al. 2005. Alternative promoters and renal cell-specific regulation of the mouse type
IIa sodium-dependent phosphate cotransporter gene. Biochim. Biophys. Acta. 1732:43-52.

24. Zhao, N., and Tenenhouse, H.S. 2000. Npt2 gene disruption confers resistance to the inhibitory action of parathyroid hormone on renal sodium-phosphate cotransport. Endocrinology. 141:2159-2165.

25. Inoue, Y., et al. 2005. Role of the vitamin D receptor in FGF23 action on phosphate metabolism. Biochem. J. 390:325-331.

26. Ito, M., et al. 2005. Vitamin D and phosphate regulate fibroblast growth factor- 23 in K-562 cells. Am. J. Physiol. Endocrinol. Metab. 288:E1101-E1109.

27. Ovchinnikov, D.A., Deng, J.M., Ogunrinu, G., and Behringer, R.R. 2000. Col2a1-directed expression of Cre recombinase in differentiating chondrocytes in transgenic mice. Genesis. 26:145-146.

28. Maes, C., et al. 2002. Impaired angiogenesis and endochondral bone formation in mice lacking the vascular endothelial growth factor isoforms

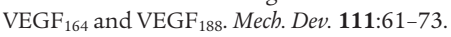

29. Daci, E., Verstuyf, A., Moermans, K., Bouillon, R., and Carmeliet, G. 2000. Mice lacking the plasminogen activator inhibitor 1 are protected from trabecular bone loss induced by estrogen deficiency. J. Bone Miner. Res. 15:1510-1516.

30. Maes, C., et al. 2004. Soluble VEGF isoforms are essential for establishing epiphyseal vascularization and regulating chondrocyte development and survival. J. Clin. Invest. 113:188-199. doi:10.1172/ JCI200419383.

31. Masuyama, R., et al. 2003. Dietary calcium and phosphorus ratio regulates bone mineralization and turnover in vitamin D receptor knockout mice by affecting intestinal calcium and phosphorus absorption. J. Bone Miner. Res. 18:1217-1226.

32. Custer, M., Lotscher, M., Biber, J., Murer, H., and Kaissling, B. 1994. Expression of Na-P(i) cotransport in rat kidney: localization by RTPCR and immunohistochemistry. Am. J. Physiol. 266:F767-F774.

33. Daci, E., Udagawa, N., Martin, T.J., Bouillon, R., and Carmeliet, G. 1999. The role of the plasminogen system in bone resorption in vitro. J. Bone Miner. Res. 14:946-952.

34. Miyamoto, K., et al. 2003. Prostaglandin $\mathrm{E}_{2}$-mediated anabolic effect of a novel inhibitor of phosphodiesterase 4, XT-611, in the in vitro bone marrow culture. J. Bone Miner. Res. 18:1471-1477. 